\title{
Éthiopie. La harpe du roi David (The Harp of King
}

David)

Long Distance, 1995

\section{Laurent Aubert}

\section{OpenEdition}

Journals

Édition électronique

URL : http://journals.openedition.org/ethnomusicologie/1250

ISSN : 2235-7688

Éditeur

ADEM - Ateliers d'ethnomusicologie

Édition imprimée

Date de publication : 31 décembre 1995

Pagination : 260-261

ISBN : 2-8257-0537-3

ISSN : $1662-372 X$

Référence électronique

Laurent Aubert, «Éthiopie. La harpe du roi David (The Harp of King David) », Cahiers d'ethnomusicologie [En ligne], 8 | 1995, mis en ligne le 04 janvier 2012, consulté le 30 avril 2019. URL : http:// journals.openedition.org/ethnomusicologie/1250

Ce document a été généré automatiquement le 30 avril 2019

Tous droits réservés 


\section{Éthiopie. La harpe du roi David (The Harp of King David)}

Long Distance, 1995

Laurent Aubert

\section{RÉFÉRENCE}

Éthiopie. La harpe du roi David (The Harp of King David). Bägänna d'Éthiopie. 1 CD Long Distance 142009, 1995.

1 La collection Long Distance animée par Alain Weber et Armand Amar est en train de s'imposer comme une des plus dynamiques du marché français actuel dans le domaine des musiques dites traditionnelles. Ce disque récent sur la « harpe du Roi David» est un bon exemple de son éclectisme et de son ouverture à des formes mal connues, voire menacées de disparition. Soutenu par les notes vibrantes du bägänna - qui, contrairement à ce qu'indique le titre du disque, est une lyre et non une harpe -, l'art confidentiel d'Alemu Aga témoigne d'un univers poétique savoureux, dans lequel les doubles sens et les sous-entendus sont la meilleure façon de parler à ceux qui ont des oreilles pour entendre. De sa voix au timbre grave et voilé, il transmet à ses auditeurs la parcelle de sagesse et de mémoire populaire qui lui est échue, avec le naturel et la simplicité de ceux qui n'ont rien à démontrer.

Cette édition semble cependant mériter quelques critiques : tout d'abord la moindre des choses pour un disque dédié à un soliste aussi respectable serait d'indiquer son nom sur la couverture, d'autant plus que, comme le rappelle l'auteur de la notice, cet aède inspiré avait déjà eu les honneurs de la collection de l'UNESCO il y a plus de vingt ans (Éthiopie III. Trois traditions de cordophones; LP Musicaphon DM 30 SL 2314, s.d., Collection UNESCO. Plages 1-5: «Le bägänna [lyre]» par Alemu Aga. Enregistrements et commentaires de Cynthia Tse Kimberlin); par ailleurs, s'il est certes méritoire de faire figurer ici les paroles intégrales d'un des douze chants en version trilingue (amharique, français et 
anglais), on aurait aimé pouvoir connaître la traduction, ne serait-ce que du titre, des onze autres! A quoi bon nous ouvrir les portes d'un jardin secret aussi parfumé si c'est pour nous priver de la jouissance de ses senteurs?

3 Les enregistrements éthiopiens réalisés par Cynthia Tse-Kimberlin pour l'UNESCO cités plus haut demeurent hélas pour l'instant inaccessibles en $\mathrm{CD}$; signalons en revanche à ceux qui désireraient élargir leur abord de cette musique que ceux provenant des missions effectuées entre 1962 et 1966 par Jean Jenkins viennent de faire l'objet de deux rééditions bienvenues, l'une chez Ocora (Ethiopie. Musiques vocales et instrumentales, C 580055/56), et l'autre dans la World Series de Topic Records (Music from Ethiopia. The central highlands, the desert nomads \& Eritrea, TSCD 910, distribué en France par Night and Day). Mentionnons enfin une autre réédition de musique éthiopienne chez Le Chant du Monde (coll. CNRS/Musée de l'Homme, 1995) celle, revue et augmentée, des Polyphonies des Dorzé enregistrées au début des années 1970 par Bernard Lortat-Jacob (CNR 274646). 